\title{
Recent Advances in the Synthesis of Difluoromethylated Arenes
}

\author{
Peng $X u^{a, b}$ \\ Shuo Guo ${ }^{\mathrm{a}, \mathrm{b}}$ \\ Liyan Wang ${ }^{\mathrm{a}, \mathrm{b}}$ \\ Pingping Tang*a,b \\ a State Key Laboratory and Institute of Elemento-Organic Chemistry, \\ Nankai University, Tianjin 300071, P. R. of China \\ ptang@nankai.edu.cn \\ b Collaborative Innovation Center of Chemical Science and Engineering, \\ Tianjin 300071, P. R. of China
}<smiles></smiles>

Received: 16.07.2014

Accepted: 24.07.2014

Published online: 21.08 .2014

DOI: 10.1055/s-0034-1378651; Art ID: st-2014-p0598-sp

\begin{abstract}
The growing importance of fluorinated compounds in pharmaceuticals, agrochemicals, and materials has triggered the development of new methods for the introduction of fluorine into small molecules. Although it is a challenge to prepare fluorinated compounds, new developed reactions are addressing this challenge and facilitating the synthesis of difluoromethylated arenes. In this article, we highlight recently important developments in the synthesis of difluoromethylated arenes.

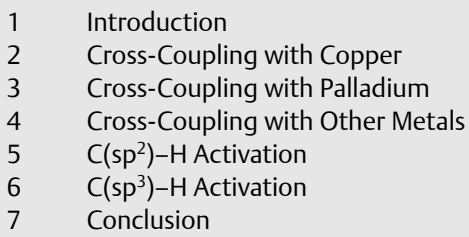

Key words fluorine, cross-coupling, palladium, copper, radicals

\section{Introduction}

The difluoromethyl group has received a great deal of attention in medicinal chemistry because it is isosteric and isopolar with the hydroxyl group and is found in various biologically active compounds (Figure 1 ). ${ }^{1}$ Generally, methods for the synthesis of difluoromethylated arenes through deoxyfluorination of aldehydes or ketones suffer from poor functional-group compatibility and require the use of expensive and toxic fluorinated reagents. ${ }^{2}$ Recent developments in organo- and transition-metal catalysis have allowed new methods to prepare difluoromethylated arenes. ${ }^{3}$ Herein we highlight recent progress in the synthesis of difluoromethylated arenes.

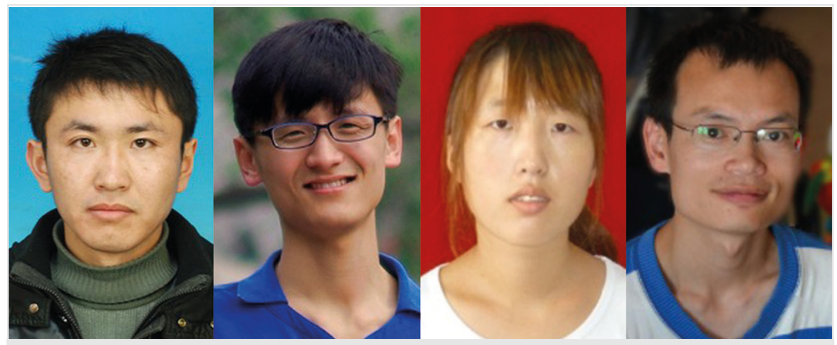

Peng Xu (left) was born in Jiangsu Province, P. R. of China in 1990. He obtained his BSc degree from jiangnan University in 2012 and then joined Professor Pingping Tang's research group in Nankai University to pursue his PhD degree. His current research interests focus on fluorine chemistry.

Shuo Guo (middle left) was born in Hebei Province, P. R. of China in 1986. He received his BSc degree from Hebei Normal University in 2010 and MSc degree from Zhengzhou University in 2013, under the supervision of Professor Yangjie Wu. Since 2013 he joined Professor Pingping Tang's research group in Nankai University to pursue his PhD degree. $\mathrm{He}$ is currently interested in carbon-fluorine bond-formation reactions based on $\mathrm{C}-\mathrm{H}$ activation.

Liyan Wang (middle right) was born in Shandong Province, P. R. of China in 1990. She obtained her BSc degree from Shandong University of Science and Technology in 2013 and then joined Professor Pingping Tang's research group in Nankai University to pursue her MSc degree. Her current research interests focus on fluorine chemistry.

Pingping Tang (right) received his BSc degree from Nankai University in 2002. After obtaining his PhD degree in 2007 working with Professor Biao Yu at Shanghai Institute of Organic Chemistry, Chinese Academy of Sciences, he worked as a postdoctoral fellow with Professor Tobias Ritter at Harvard University (2008-2012). Since 2012, he joined the State Key Laboratory and Institute of Elemento-Organic Chemistry at Nankai University as a professor. His research interests include fluorine chemistry and total synthesis of biologically important small molecules.<smiles>COc1ccnc(CS(=O)c2nc3cc(OC(F)F)ccc3[nH]2)c1OC</smiles>

pantoprazole

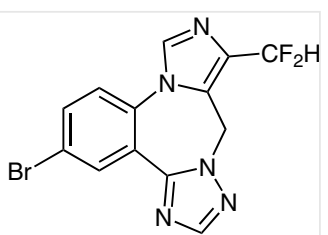

R04938581
Figure 1 Representative drug and drug candidate containing $\mathrm{CF}_{2} \mathrm{H}$ functional group 


\section{Cross-Coupling with Copper}

Recently, Amii and co-workers reported a copper-catalyzed cross-coupling and decarboxylation from aryl iodides to prepare difluoromethylated arenes (Scheme 1, a). ${ }^{4}$ Although cross-coupling with $\alpha$-silyldifluoroacetates was achieved under mild conditions, the decarboxylation step is limited to electron-deficient aryl iodides and requires high temperature $\left(>170{ }^{\circ} \mathrm{C}\right)$. The copper-catalyzed cross-coupling of ethyl ortho-iodobenzoates with bromozinc-difluorophosphonates was reported by Zhang and co-workers. ${ }^{5}$ The benzoate ester directing group plays important roles, and the features of this reaction are the high reaction efficiency, excellent functional-group compatibility, and operational simplicity. Hartwig and co-workers presented a one-step copper-mediated cross-coupling between iodoarenes and $\mathrm{TMSCF}_{2} \mathrm{H}$ (Scheme 1, b). ${ }^{6}$ Although the reaction proceeds in high yields with good functional-group compatibility, the reaction requires a large excess amount of $\mathrm{TMSCF}_{2} \mathrm{H}$ (5 equiv) and is limited to electron-rich and electron-neutral iodoarenes. These problems were addressed successfully by Surya Prakash with $n-\mathrm{Bu}_{3} \mathrm{SnCF}_{2} \mathrm{H}$ as the difluoromethyl pronucleophile (Scheme $1, \mathrm{c}$ ). ${ }^{7}$ The disadvantages of the method are that the reaction requires high temperature and $n-\mathrm{Bu}_{3} \mathrm{SnCF}_{2} \mathrm{H}$ is toxic. Shen and Lu developed a copper-mediated ligandless aerobic fluoroalkylation of arylboronic acids under mild conditions to prepare difluoromethylated arenes. ${ }^{8}$ The reaction tolerates a wide range of functional groups and can be easily scaled up. Recently, Qing's group reported a copper-mediated direct difluoromethylation of electron-deficient aryl iodides using 2.4 equivalents of $\mathrm{TMSCF}_{2} \mathrm{H}$ at room temperature (Scheme 1 , d). ${ }^{9}$ The mild reaction conditions make this method attractive for the synthesis of difluoromethylated arenes.

\section{Cross-Coupling with Palladium}

Early this year, Zhang and co-workers described a palladium-catalyzed difluoroallylation of aryl boronic acid using 3-bromo-3,3-difluoropropene (Scheme 2, a).${ }^{10}$ The reaction proceeds with low catalyst loading, high regioselectivity, and excellent functional-group compatibility. At the same time, the authors also reported another palladium-catalyzed difluoroalkylation of aryl boronic acid with bromodifluoromethylphosphonate, bromodifluoroacetate, and further derivatives, which provides a facile and useful access to a series of functionalized difluoromethylated arenes. ${ }^{11}$ Qing and co-workers reported a palladium-catalyzed directed $\alpha$-arylation of $\alpha, \alpha$-difluoro ketones with aryl bromides. ${ }^{12}$ The method provides an efficient and straightforward access to a variety of difluoromethylated arenes with broad (a)

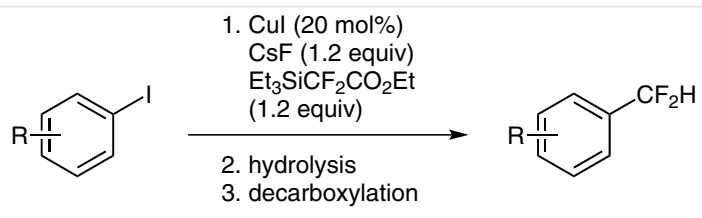

(b)

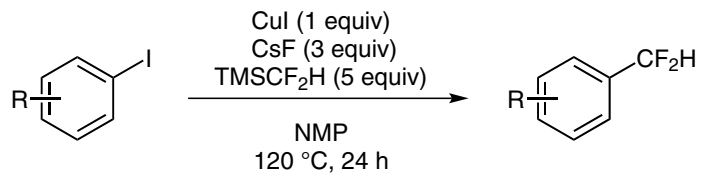

(c)

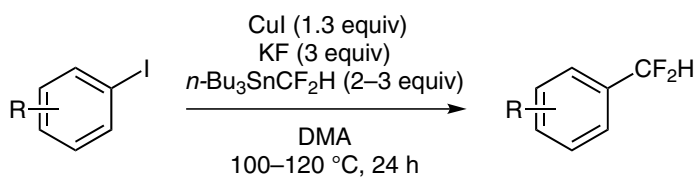

(d)

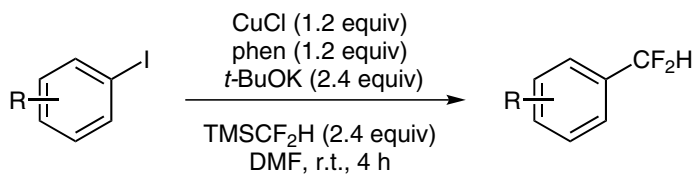

Scheme 1 Difluoromethylation of (hetero)aryl iodides with copper

substrate scope. The disadvantage of the method is that the reaction required high temperature and high catalyst loading. This problem was addressed successfully by Hartwig and co-workers with an air- and moisture-stable palladacyclic complex as a catalyst, a broad range of electronically varied aryl bromides and chlorides was used to provide difluoromethylated arenes in high yields with low catalyst loading and lower temperature (Scheme $2, \mathrm{~b}$ ). ${ }^{13}$ (a)

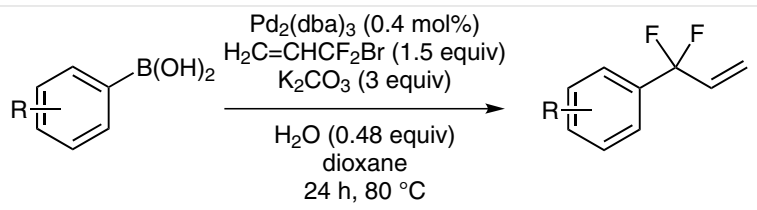

(b)<smiles></smiles>
$\mathrm{X}=\mathrm{Br}, \mathrm{Cl}$
Pd complex (1-2 mol\%) $\mathrm{PhC}(\mathrm{O}) \mathrm{CF}_{2} \mathrm{H}$

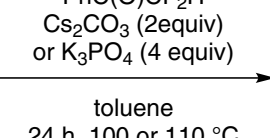
$24 \mathrm{~h}, 100$ or $110^{\circ} \mathrm{C}$

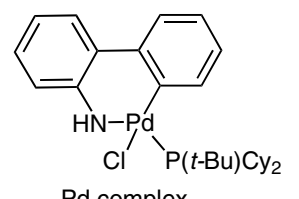

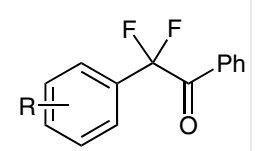

(1)
Scheme 2 Formation of difluoromethylated arenes with palladium 


\section{Cross-Coupling with Other Metals}

In 2012, Li and co-workers reported a silver-catalyzed decarboxylative fluorination of aliphatic carboxylic acids with Selectfluor under mild conditions. ${ }^{14}$ Using Li's method, the transformation of $\alpha$-fluoroarylacetic acids into difluoromethylated arenes was achieved by Gouverneur and co-workers (Scheme 3, a). ${ }^{15}$ This method allows for the preparation of $\left[{ }^{18} \mathrm{~F}\right]$-labeled difluoromethylarenes using $\left[{ }^{18} \mathrm{~F}\right]-$ Selectfluor bistriflate. Inoue and co-workers reported a cobalt-catalyzed cross-coupling reaction of arylzinc reagents with ethyl bromodifluoroacetate to form difluoromethylated arenes (Scheme 3, b) ${ }^{16}$ The reaction proceeds under mild conditions and is applicable to various arylzinc reagents to afford the corresponding ethyl aryldifluoroacetates.

(a)

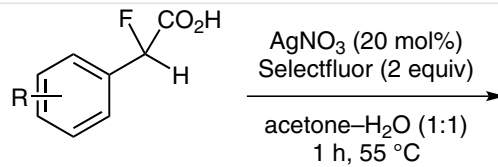

(b)

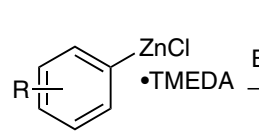

(2 equiv)
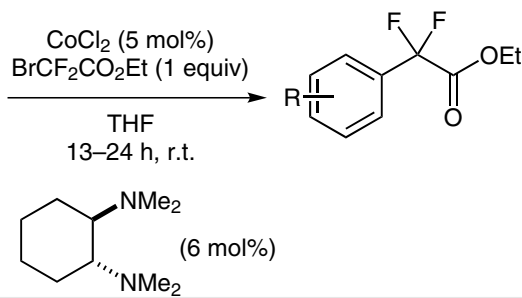

Scheme 3 Formation of difluoromethylated arenes with other metals

\section{$5 \mathrm{C}\left(\mathrm{sp}^{2}\right)-\mathrm{H}$ Activation}

Recently, directed ethoxycarbonyldifluoromethylation of aromatic compounds with $\mathrm{BrCF}_{2} \mathrm{CO}_{2}$ Et was reported using $\mathrm{Cp}_{2}$ Fe by Testu Yamakawa and co-workers. ${ }^{17}$ Moreover, the one-pot synthesis of 3,3-difluoro-2,3-dihydroindole-2one derivatives was achieved with para-substituted aniline derivatives using this method. Baran and co-workers reported a directed difluoromethylation of $\mathrm{C}-\mathrm{H}$ bonds in heteroarenes with benchtop-stable $\mathrm{Zn}\left(\mathrm{SO}_{2} \mathrm{CF}_{2} \mathrm{H}\right)_{2}$ (Scheme 4, a). ${ }^{18}$ Shortly after, the authors developed other new reagents, such as sodium difluoroethylsulfinate, for the synthesis of fluorinated heteroarenes. ${ }^{19}$ Early this year, Wang and co-workers developed a new method for visible-light photoredox difluoromethylation of electron-rich heteroarenes under mild conditions (Scheme 4, b) ${ }^{20}$ Mechanistic investigation indicated that the reaction proceeds through an electrophilic radical-type pathway. (a)<smiles>c1ccccc1</smiles>

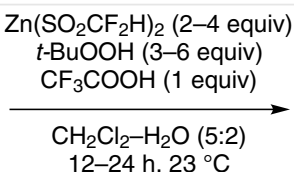<smiles>FCc1ccccc1</smiles>
$12-24 \mathrm{~h}, 23^{\circ} \mathrm{C}$<smiles>c1ccccc1</smiles>
$\mathrm{Rh}(\mathrm{bpy})_{3} \mathrm{Cl}_{2} \cdot 6 \mathrm{H}_{2} \mathrm{O}(1 \mathrm{~mol} \%)$ $\mathrm{PhSO}_{2} \mathrm{CF}_{2} \mathrm{I}$ (1 equiv) $\mathrm{K}_{2} \mathrm{HPO}_{4}$ (3 equiv) visible light, $\mathrm{CH}_{2} \mathrm{Cl}_{2}$<smiles>FCc1ccc(F)cc1</smiles>
(2 equiv) $24 \mathrm{~h}, 40^{\circ} \mathrm{C}$

Scheme 4 Formation of difluoromethylated arenes via $\mathrm{C}\left(\mathrm{sp}^{2}\right)-\mathrm{H}$ activation

\section{$6 \mathrm{C}\left(\mathrm{sp}^{3}\right)-\mathrm{H}$ Activation}

In 2013, Chen and co-workers reported a visible-lightpromoted metal-free $\mathrm{C}-\mathrm{H}$ activation for the synthesis of difluoromethylated arenes (Scheme 5, a). ${ }^{21}$ This is the first report of selective $\mathrm{C}-\mathrm{H}$ gem-difluorination. Shortly after, we reported a silver-catalyzed oxidative activation of benzylic $\mathrm{C}-\mathrm{H}$ bonds to synthesize difluoromethylated arenes (Scheme 5, b). ${ }^{22}$ With $\mathrm{AgNO}_{3}$ as the catalyst, the reaction of a variety of methylated arenes with Selectfluor and $\mathrm{Na}_{2} \mathrm{~S}_{2} \mathrm{O}_{8}$ in acetonitrile-water $(\mathrm{v} / \mathrm{v}=1: 1)$ at $80{ }^{\circ} \mathrm{C}$ under nitrogen atmosphere led to the formation of the corresponding difluoromethylated arenes in 42-93\% isolated yield. (a)<smiles>[R]C([2H])c1cc#[R]cc1</smiles>

(b)

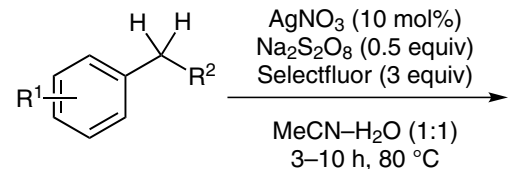<smiles>[R]C(F)(F)c1cc[nH][cH+]c1</smiles><smiles>[R]C(F)(F)c1ccncc1</smiles>

Scheme 5 Formation of difluoromethylated arenes via $\mathrm{C}\left(\mathrm{sp}^{3}\right)-\mathrm{H}$ activation

Some representative examples are shown in Scheme 6. The mild reaction conditions generally tolerate diverse functional groups on the aryl rings. Notably, the reaction is amenable to gram-scale synthesis, proving the practicality of our method. The preliminary mechanism studies indicate that a radical-chain mechanism or single-electron transfer (SET) may be involved in this transformation. 


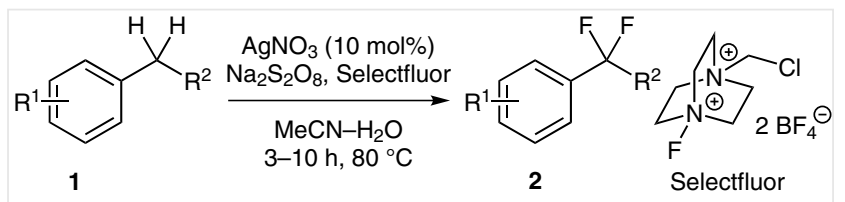<smiles>FC(F)(F)c1ccccc1</smiles><smiles>NS(=O)(=O)c1ccc([18F])cc1</smiles>

2b, $64 \%$

2a, $85 \%$<smiles>FC(F)(F)c1ccc(-c2ccccc2)cc1</smiles>

2d, $93 \%$<smiles>O=C(O)c1ccccc1C(F)(F)F</smiles>

2e, $87 \%$<smiles>NC(=O)c1ccc(C(F)(F)F)cc1</smiles>

2c, $72 \%$<smiles>CC(=O)c1ccccc1C(F)(F)F</smiles>

2g, $87 \%$<smiles>NC(=O)c1ccccc1C(F)(F)F</smiles>

2h, $69 \%$<smiles>CC(F)(F)c1ccccc1C(=O)O</smiles>

2j, $82 \%$ 2k, $71 \%$<smiles>NC(=O)CC(F)(F)c1ccccc1</smiles>

2I, $42 \%$

Scheme 6 Silver-catalyzed benzylic C-H activation for the synthesis of difluoromethylated arenes by Tang and $\mathrm{Xu}$ (representative examples)

\section{Conclusion}

To summarize, significant advances have been made in the synthesis of difluoromethylated arenes. Particularly, recent advances have allowed innovative approaches for benzylic C-H fluorination to prepare difluoromethylatd arenes. However, some challenges still remain. Such as directed introduction of the difluoromethyl group to arene through $\mathrm{C}-\mathrm{H}$ activation is still not efficient. New metal catalysts such as iron are still required. These challenges are expected to stimulate further development in the synthesis of difluoromethylated arenes.

\section{Acknowledgment}

We gratefully thank the State Key Laboratory of Elemento-Organic Chemistry for generous start-up financial support. This work was supported by the ' 1000 Youth Talents Plan', and the Natural Science Foundation of Tianjin (Grant No. 13JCYBJC36500).

\section{References}

(1) (a) Erichson, J. A.; McLoughlin, J. I. J. Org. Chem. 1995, 60, 1626. (b) Knust, H.; Achermann, G.; Ballard, T.; Buettelmann, B.; Gasser, R.; Fischer, H.; Hernandez, M.-C.; Knoflach, F.; Koblet, A.; Stadler, H.; Thomas, A. W.; Trube, G.; Waldmeier, P. Bioorg. Med. Chem. Lett. 2009, 19, 5940. (c) Meanwell, N. A. J. Med. Chem. 2011, 54, 2529; and references cited therein.

(2) (a) Markovski, L. N.; Pahinnik, V. E.; Kirsanov, A. V. Synthesis 1973, 787. (b) Middleton, W. J. J. Org. Chem. 1975, 40, 574. (c) Singh, R. P.; Sheeve, J. M. J. Org. Chem. 2003, 68, 6063. (d) Umemoto, T.; Singh, R. P.; Xu, Y.; Saito, N. J. Am. Chem. Soc. 2010, 132, 18199.

(3) For the latest selected reviews, see: (a) Hu, J.; Zhang, W.; Wang, F. Chem. Commun. 2009, 7465. (b) Liang, T.; Neumann, C.; Ritter, T. Angew. Chem. Int. Ed. 2013, 52, 8214.

(4) Fujikawa, K.; Fujioka, Y.; Kobayashi, A.; Amii, H. Org. Lett. 2011, $13,5560$.

(5) Feng, Z.; Chen, F.; Zhang, X. Org. Lett. 2012, 14, 1938.

(6) Fier, P. S.; Hartwig, J. F. J. Am. Chem. Soc. 2012, 134, 5524.

(7) Surya Prakash, G. K.; Ganesh, S. K.; Jones, J. P.; Kulkarni, A.; Masood, K.; Swabeck, J. K.; Olah, G. A. Angew. Chem. Int. Ed. 2012, 51, 12090.

(8) Qi, Q.; Shen, Q.; Lu, L. J. Am. Chem. Soc. 2012, 134, 6548.

(9) Jiang, X.; Chen, Z.; Xu, X.; Qing, F. Org. Chem. Front. 2014, 1, 774.

(10) Min, Q.; Yin, Z.; Feng, Z.; Guo, W.; Zhang, X. J. Am. Chem. Soc. 2014, 136, 1230.

(11) Feng, Z.; Min, Q.; Xiao, Y.; Zhang, B.; Zhang, X. Angew. Chem. Int. Ed. 2014, 53, 1669.

(12) Guo, C.; Wang, R.; Qing, F. J. Fluorine Chem. 2012, 143, 135.

(13) Ge, S.; Chaladaj, W.; Hartwig, J. F. J. Am. Chem. Soc. 2014, 136, 4149.

(14) Yin, F.; Wang, Z.; Li, Z.; Li, C. J. Am. Chem. Soc. 2012, 134, 10401.

(15) Mizuta, S.; Stenhagen, I. S. R.; O’Duill, M.; Wolstenhulme, J.; Kirjavainen, A. K.; Forsback, S. J.; Tredwell, M.; Sandford, G.; Moore, P. R.; Huiban, M.; Luthra, S. K.; Passchier, J.; Solin, O.; Gouverneur, V. Org. Lett. 2013, 15, 2648.

(16) Araki, K.; Inoue, M. Tetrahedron 2013, 69, 3913.

(17) Ohtsuka, Y.; Yamakawa, T. Tetrahedron 2011, 67, 2323.

(18) Fujiwara, Y.; Dixon, J. A.; Rodriguez, R. A.; Baxter, R. D.; Dixon, D. D.; Collins, M. R.; Blackmond, D. G.; Baran, P. S. J. Am. Chem. Soc. 2012, 134, 1494.

(19) Zhou, Q.; Ruffoni, A.; Gianatassio, R.; Fujiwara, Y.; Sella, E.; Shabat, D.; Baran, P. S. Angew. Chem. Int. Ed. 2013, 52, 3949.

(20) Su, Y.; Hou, Y.; Yin, F.; Xu, Y.; Li, Y.; Zheng, X.; Wang, X. Org. Lett. 2014, 16, 2958.

(21) Xia, J.; Zhu, C.; Chen, C. J. Am. Chem. Soc. 2013, 135, 17494.

(22) Xu, P.; Guo, S.; Wang, L.; Tang, P. Angew. Chem. Int. Ed. 2014, 53, 5955.

This article differs from the e-first online version only in its layout; no content has been changed. 